\title{
Evapotranspiration and water availability response to climate change in the Middle East and North Africa
}

\author{
Salah Basem Ajjur ${ }^{1}$ (D) Sami G. Al-Ghamdi ${ }^{1}$ \\ Received: 19 November 2020 / Accepted: 10 May 2021 / Published online: 2 June 2021 \\ (C) The Author(s) 2021
}

\begin{abstract}
Quantifying the impact of climate change on evapotranspiration is necessary for devising accurate water and energy budgets in light of global warming. Nevertheless, in the Middle East and North Africa (MENA), little has been done to bridge this gap. This study, then, implements Penman and Budyko approaches to climatic data retrieved from the sixth phase of the Coupled Model Intercomparison Project (CMIP6) to assess evapotranspiration and water availability evolutions through the twenty-first century. Outcomes reveal that the MENA region is indeed vulnerable to a surge in temperature, which can increase evapotranspiration losses and decrease water availability. Under the shared socioeconomic pathway (SSP2-4.5), the potential evapotranspiration (PET) has been projected to increase throughout the MENA region by up to $0.37 \mathrm{~mm}$ per year during the middle of the twenty-first century (2021-2050) and by up to $0.51 \mathrm{~mm}$ per year during the end of the twenty-first century (2071-2100). Meanwhile, the actual evapotranspiration (AET) has been projected to increase by up to $0.3(\sim 0.2) \mathrm{mm}$ per year before 2050 (2100). The trends in both projections (PET and AET) are exaggerated under SSP58.5. The analysis predicted a shortage of water availability (precipitation-AET), which is alarming for most MENA regions. Relative to the reference period (1981-2010), the decline in annual water availability would reach 26 (62) $\mathrm{mm}$ by 2100 under SSP2-4.5 (SSP5-8.5). The rise in temperatures appears to be the principal reason for MENA and
\end{abstract}

\footnotetext{
Key points

-The Middle East and North Africa region are vulnerable to a surge in temperature, which can increase evapotranspiration losses and decrease water availability.

-The shortage of water availability (precipitation - actual evapotranspiration) is alarming for the Arabian Gulf region.

-The rise in temperatures appears to be the principal reason for evapotranspiration and water availability responses.
}

Salah Basem Ajjur

saajjur@hbku.edu.qa; sajjur2010@students.iugaza.edu.ps

Sami G. Al-Ghamdi

salghamdi@hbku.edu.qa

1 Division of Sustainable Development, College of Science and Engineering, Hamad Bin Khalifa University, Doha, Qatar 
water availability responses. This study's outcomes can facilitate accurate and realistic predictions related to evapotranspiration and water availability, which are key elements in not only managing water resources but also in devising effective climate change mitigation and adaptation plans.

Keywords Climate change Potential evapotranspiration - Actual evapotranspiration - Water deficits $\cdot$ CMIP6 $\cdot$ Middle East and MENA Africa region

\section{Introduction}

Evapotranspiration refers to water movement from land to atmosphere through two processes: (1) evaporation from water surfaces and soil and (2) transpiration from plants. The evapotranspiration phenomenon is of high interest in many disciplines, including hydrology, agriculture, energy budget, and climate studies. It is a required component when identifying irrigation demands and runoff quantities ( $\mathrm{Li}$ et al. 2020), when looking into an energy budget for the earth-atmosphere system (Diak et al. 2004), when improving the predictions of atmospheric circulation models (Pielke et al. 2003), and when undergoing climatic characterization (Wang et al. 2017). Accurate estimations of evapotranspiration enable farmers to apply suitable crop water requirements, which saves water, energy, and chemicals apart from preventing regional environmental contaminations. Erroneous estimations, by contrast, lead to poor irrigation practices (water shortages or waterlogging) that adversely affect crop yields (Rahimi-Moghaddam et al. 2018). The two terms mainly used to describe evapotranspiration are actual evapotranspiration (AET) and potential evapotranspiration (PET). The AET is computed under nonstandard (i.e., real) environmental and management conditions. Its measurement is complex, time-consuming, and costly, primarily because it depends on climatic parameters, plant properties, and environmental conditions (Goya and Harmsen 2014). Meanwhile, PET is calculated under standard conditions - in a uniform and completely vegetated area with a permanent water supply and shading.

Studying trends of evapotranspiration is challenging. No linear relationship can be generated between evapotranspiration and its controlling factors. Evapotranspiration estimation correlates with several influences, such as temperature and rainfall (Tabari and Talaee 2014), relative humidity (Gong et al. 2006), vapor pressure (Irmak et al. 2006), and land use (Eichelmann et al. 2018). The relevant literature, which has forecasted the trend in global evapotranspiration, displays some discrepancies (Anabalón and Sharma 2017; Dong and Dai 2016). For instance, while Wang et al. (2010) observed an increase of $15 \mathrm{~mm}$ per year in global land evapotranspiration from 1982 to 2002, Jung et al. (2010) noted a rise in evapotranspiration of $7.1 \pm 1 \mathrm{~mm}$ per year from 1982 to 1997; this rise ceased between 1998 and 2008, though Zhang et al. (2019) asserted that global evapotranspiration increased significantly between 2002 and 2017. Future projections of evapotranspiration vary substantially across regions. By 2100, Brêda et al. (2020) projected a decrease in overall evapotranspiration in South America, whereas Sullivan et al. (2019) projected increased evapotranspiration in North America. Other studies (see Mueller and Seneviratne 2014; Sullivan et al. 2019) reported substantial biases in evapotranspiration simulations from the fifth phase of the Coupled Model Intercomparison Project (CMIP5). Mueller and Seneviratne (2014) reported that 14 CMIP5 models produced a systematic overestimation bias in global evapotranspiration projections of 
$0.17 \mathrm{~mm}$ per day on average. This bias underestimated evapotranspiration values in the Northern Hemisphere.

Accordingly, it is essential to evaluate evapotranspiration behavior under climate change on regional scales - particularly in the Middle East and North Africa (MENA) region, which is highly projected to climatic changes through the twenty-first century. These changes include a significant increase in temperatures and warm days, heat extremes, longevity of drought periods, and precipitation extremes in several regions (Ajjur and Riffi 2020; Lelieveld et al. 2016; Zittis 2017). Climatic changes can intensify evapotranspiration losses and regional water deficits (Erol and Randhir 2012). The MENA region consists predominantly of hyper-arid areas; therefore, several given methods for evapotranspiration estimation, such as Priestley and Taylor's (1972) and Makkink's (1957), are inapplicable (Goya and Harmsen 2014). Other methods, including Blaney and Criddle (1950), Hargreaves and Samni (1982), and Dalton (1802), may be unreliable (Li et al. 2016). A number of reliable methods, such as those that are physically based, demand extensive meteorological data that are not readily available in the MENA region, as those data provide neither sufficient coverage nor good quality (Zittis 2017). Li et al. (2016) evaluated the performance of six models for estimating PET in arid northwest China. They found that Penman (1948) and Shuttleworth (1993) are more reliable and accurate methods.

As such, this study used climatic data from an ensemble comprising 10 models in the CMIP6 to forecast the variations in PET, AET, and water availability across the MENA region throughout the twenty-first century. Two periods were considered for future projections: 2021-2050 (hereafter referred to as the mid-twenty-first century) and 2071-2100 (hereafter referred to as the end-twenty-first century). Two shared socioeconomic pathways (SSPs) were selected to simulate future projections from each model: SSP2-4.5 and SSP5-8.5. The study outcomes are key factors in managing water resources as well as in establishing climate change mitigation and adaptation plans.

\subsection{Study area}

According to the World Bank, the MENA region $\left(12^{\circ} \mathrm{N}-40^{\circ} \mathrm{N}, 12^{\circ} \mathrm{W}-63^{\circ} \mathrm{E}\right)$ comprises 19 countries extending from Iran in the east to Morocco in the west (see Fig. 1). The MENA region has several common characteristics in terms of water resources and climate but is diverse in geography, natural resources, economic activities, and land use. Generally, MENA is one of the most water-stressed regions in the world. The average water availability in the MENA region is $1000 \mathrm{~m}^{3}$ of freshwater per capita per year, whereas the global average exceeds $7000 \mathrm{~m}^{3}$ (World Bank 2020). Anthropogenic stresses continue to pose pressure on water resources. During the last half-century, the population across MENA quadrupled, while urbanization nearly doubled (World Bank 2020). Most of the MENA region lies under hot desert class (BWh) as categorized by the Köppen climate classification (Peel et al. 2007). Based on an ensemble that comprises 10 CMIP6 models used in this study, MENA's mean near-surface air temperature (hereafter referred to as temperature) ranged between 5 and $31^{\circ} \mathrm{C}$, while MENA's annual rainfall varied up to $231 \mathrm{~mm}$ from 1981 to 2010.

\section{Data}

Maximum and minimum temperature, precipitation, wind speed, radiation, and relative humidity simulations were obtained from 10 Atmosphere-Ocean General Circulation Models 


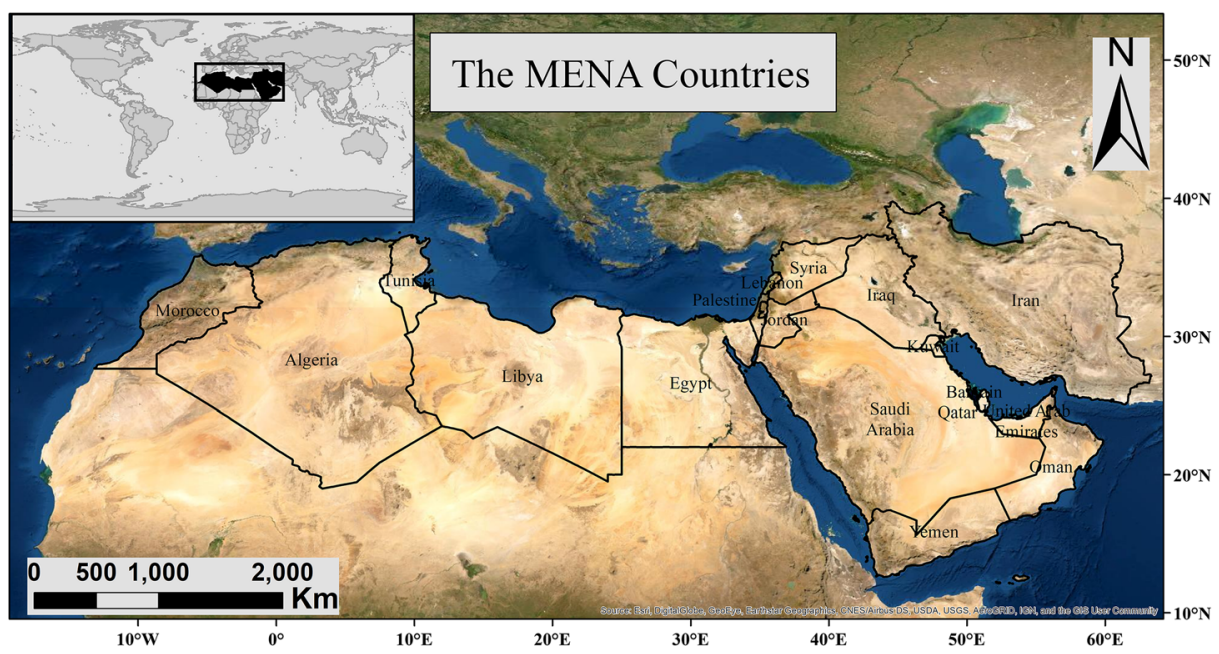

Fig. 1 The general location of the Middle East and North Africa (MENA) region and MENA countries. The map was generated using ArcGIS 4.1 (http://www.esri.com)

(AOGCMs) from CMIP6. Table 1 presents information about these models, including their institutions, countries, and horizontal resolution. The model data were retrieved from the archive of the earth system grid federation online system (https://esgf-node.llnl.gov/search/ cmip6/). Two SSPs were selected to simulate future projections from each model. These reflected the intermediate mitigation scenario (SSP2-4.5) and the very high greenhouse gas (GHG) emissions scenario (SSP5-8.5) as prescribed by the Intergovernmental Panel on Climate Change (IPCC 2014). The SSP2-4.5 (SSP5-8.5) considers a radiative forcing of 4.5 (8.5) Watts per square meter $\left(\mathrm{W} \mathrm{m}^{-2}\right)$ and predicts an increase of $1.8 \pm 0.7(3.7 \pm 1.1){ }^{\circ} \mathrm{C}$ globally before the twenty-second century (IPCC 2014). Unless unavailable, the r1i1p1 ensemble member was selected for each model. The CMIP6 models have different resolutions;

Table 1 The 10 AOGCM CMIP6 models used in this study, their modeling groups (institutions), countries involved, and horizontal resolution

\begin{tabular}{llll}
\hline Model acronym & The modeling group (institution), country & Institute ID & $\begin{array}{l}\text { Horizontal resolution } \\
\text { (lon. } \times \text { lat. })\end{array}$ \\
\hline CanESM5 & $\begin{array}{l}\text { Canadian Centre for Climate Modeling and Analysis } \\
\text { (Canada) }\end{array}$ & CCCma & $2.81^{\circ} \times 2.81^{\circ}$ \\
CESM2 & National Center for Atmospheric Research (USA) & NCAR & $1.25^{\circ} \times 0.93^{\circ}$ \\
GISS-E2-1-G & Goddard Institute for Space Studies (USA) & NASA-GISS & $2.5^{\circ} \times 2^{\circ}$ \\
HadGEM3 & National Environmental Research Council (UK) & NERC & $1.875^{\circ} \times 1.25^{\circ}$ \\
INM-CM5-0 & Institute for Numerical Mathematics, Russian & INM & $22^{\circ} \times 1.5^{\circ}$ \\
& $\quad$ Academy of Science (Russia) & IPSL & $2.5^{\circ} \times 1.258^{\circ}$ \\
IPSL-CM6A-LR & Institut Pierre Simon Laplace (France) & MIROC & $1.4^{\circ} \times 1.4^{\circ}$ \\
MIROC6 & Japanese modeling community (Japan) & & \\
& Atmosphere and Ocean Research Institute, & MRI & $1.125^{\circ} \times 1.125^{\circ}$ \\
& $\quad$ University of Tokyo & $0.937^{\circ} \times 0.937^{\circ}$ \\
MRI-ESM2-0 & Meteorological Research Institute (Japan) & $1.25^{\circ} \times 0.937^{\circ}$ \\
MPI-ESM1-2-HR & Max Planck Institute for Meteorology (Germany) & MPI-M & NCC \\
NorESM2-MM & Norwegian Climate Centre (Norway) & &
\end{tabular}


therefore, each model dataset was remapped to a common grid of $1^{\circ} \times 1^{\circ}$ using the bilinear interpolation method.

Several studies (Hay et al. 2000; Wu and Huang 2016; Wu et al. 2020) reported biases in climate models. They suggested correcting the bias in original CMIP data to evade unreliable climate change assessments. Therefore, we compared monthly MENA-averaged precipitation and temperature AOGCMs simulations with observation-based global datasets. For precipitation, we referred to the Global Precipitation Climatology Centre (GPCC) V2018 datasets. The GPCC data are available at $1^{\circ} \times 1^{\circ}$ grids from the National Oceanic and Atmospheric Administration's (NOAA) (https://psl.noaa.gov/data/gridded/data.gpcc.html\#detail-last access March 18, 2021). We selected the GPCC precipitation datasets because their reliability have been proven in the Mediterranean region (Nastos 2011). For maximum and minimum temperature, we referred to the Climatic Research Unit - University of East Anglia datasets (CRU TS 4.05). The CRU TS 4.05 data are available at $0.5^{\circ} \times 0.5^{\circ}$ grids from the https://sites.uea.ac.uk/cru/-last access March 18, 2021 (Harris et al. 2020). For ensuring the spatial resolution consistency, the CRU TS 4.05 datasets were bilinearly interpolated to the $1^{\circ} \times 1^{\circ}$ grids similar to the CMIP6 simulations.

\section{Methods}

The first step was to validate and correct the bias in precipitation and maximum and minimum temperatures from CMIP6 simulations according to observational datasets. Next, the corrected data in addition to relative humidity, radiation, and wind speed simulations were applied to estimate PET, AET, and water availability for both the reference and future periods. The world meteorological organization (WMO 2017) recommends the most-recent 30-year period finishing in a year ending with zero as the climatological standard normal. Thus, the period between 1981 and 2010 was selected as the reference period. Finally, the response of evapotranspiration and water availability to climatic changes during the mid-twenty-first century was defined as the difference between evapotranspiration and water availability projections for 2021-2050 and 1981-2010. Similarly, the variations during the end-twentyfirst century were defined as the difference between evapotranspiration and water availability projections for 2071-2100 and 1981-2010. No temporal downscaling was applied in CMIP6 model projections, primarily because the projection period, 30 years, is short (Dezsi et al. 2018). The analyses mentioned above were performed using the Python and ArcGIS software.

\subsection{Bias correction of CMIP6 simulations}

This study used the "delta change" method (Hay et al. 2000) to correct the bias in precipitation and temperature AOGCMs simulations. The delta change method is a common way to correct the bias in GCM simulation data (Wu and Huang 2016; Wu et al. 2021; Wu et al. 2020; Xu et al. 2019). For precipitation, original CMIP6 simulations were multiplied by a correction factor as per Eq. 1:

$$
x_{\text {corr } i, j}=x_{\text {simulated } i, j} \times \frac{\bar{x}_{\text {observed } i, j}}{\bar{x}_{\text {simulated } i, j}}
$$


where $x_{\text {corr }_{i}, j}$ is the corrected precipitation at the $j^{\text {th }}$ grid point; $x_{\text {simulated } i, j}$ is the simulated precipitation at the $j^{\text {th }}$ grid point; and $\bar{x}_{\text {observed } i, j}$ and $\bar{x}_{\text {simulated } i, j}$ are the averages of the observed and simulated precipitation, respectively, at the $j^{\text {th }}$ grid point during the reference period (1981-2010). For maximum and minimum temperature, a correction factor was added to original CMIP6 simulations as per Eq. 2:

$$
x_{\text {corr }_{i}, j}=x_{\text {simulated } i, j}+\left(\bar{x}_{\text {observed } i, j}-\bar{x}_{\text {simulated } i, j}\right)
$$

\subsection{Potential evapotranspiration estimation}

The study estimates the MENA PET using the Penman (1948) method. Penman (1948) is a widely used standard method to estimates PET and evaluate climate change impact on water resources in various locations and climatic conditions (Goya and Harmsen 2014; Li et al. 2013; Li et al. 2016; Wang et al. 2010; Wang et al. 2017; Wu et al. 2018). The Penman (1948) equation estimates PET as follows:

$$
P E T=\frac{\Delta R_{n}+6.43 \gamma\left(1+0.536 U_{2}\right)\left(1-R H_{\text {mean }}\right) e_{s}}{(\Delta+\gamma) \lambda}
$$

where $\Delta$ is the slope of vapor pressure curve in $\mathrm{kPa} /{ }^{\circ} \mathrm{C} ; R_{n}$ is the net radiation in $\mathrm{MJ} / \mathrm{m}^{2}$.day; $\gamma$ is the psychrometric constant $\left(\mathrm{kPa} /{ }^{\circ} \mathrm{C}\right) ; U_{2}$ is the wind speed at $2 \mathrm{~m}$ above the ground surface in $\mathrm{m} / \mathrm{s} ; R H_{\text {mean }}$ is the mean relative humidity in $\% ; e_{s}$ is the mean saturation vapor pressure in $\mathrm{kPa}$; and $\lambda$ is the latent heat of vaporization of water in $\mathrm{MJ} / \mathrm{kg}$.

The $R n$ is defined as the difference between incoming and outgoing radiation of both short and long wavelengths. The $R n$ can be calculated from other meteorological parameters like maximum air temperature $T_{\max }\left({ }^{\circ} \mathrm{C}\right)$, minimum air temperature $T_{\min }\left({ }^{\circ} \mathrm{C}\right)$, and $R H_{\text {mean }}$. The psychrometric constant $(\gamma)$ is valued at $\sim 0.665 \times 10^{-3} \mathrm{P}$, where $P$ is the atmospheric pressure in $\mathrm{KPa}$. The $\lambda$ equals to $2.45 \mathrm{MJ} / \mathrm{kg}$. Wind speed is simulated at a $10 \mathrm{~m}$ height in AOGCMs. Therefore, we used Eq. 4 to obtain the wind speed at $2 \mathrm{~m}$ above the surface:

$$
U_{2}=U_{z} \frac{4.87}{\ln (67.8 z-5.42)}
$$

where $u_{2}$ is the wind speed at $2 \mathrm{~m}$ above the ground surface in $\mathrm{m} / \mathrm{s} ; \mathrm{u}_{\mathrm{z}}$ is the simulated wind speed at $\mathrm{z} \mathrm{m}$ above the ground surface in $\mathrm{m} / \mathrm{s}$; and $z$ is the height of measurement above the ground surface in $\mathrm{m}$. In other words, we multiplied $\mathrm{U}_{10}$ by 0.748 to get $\mathrm{U}_{2}$. For additional information about PET calculation, the reader can refer to Doorenbos (1975); Goya and Harmsen (2014); and Penman (1948).

\subsection{Actual evapotranspiration estimation}

The annual AET was calculated using the method prescribed by Budyko and Miller (1974). Their original framework is dependent on the long-term water balance principle, where AET is controlled by precipitation and PET. Several Budyko curves were developed later with different functional shapes, but the base hypothesis for all curves is identical: water limits evapotranspiration values in dry environments, while energy limits evapotranspiration values in wet environments (Baw-Puh 1981; Choudhury 1999; Donohue et al. 2012; Yang et al. 
2008). The Budyko and Miller (1974) method is valuable for assessing climate change and surface condition impacts on water resources in scarce-data regions (Li et al. 2013; Williams et al. 2012; Yang et al. 2008; Zhang et al. 2001). This study applied PET and precipitation data to estimate the annual AET using the common Budyko Fu formula (Baw-Puh 1981) (Eq. 5):

$$
A E T=P+P E T-\left(P^{\omega}+P E T^{\omega}\right)^{\frac{1}{\omega}}
$$

where $P$ and $P E T$ are the annual precipitation and annual $P E T$, respectively. Since precipitation data (projected from CMIP6) and PET data (calculated) have monthly time scales, all precipitations and PET outputs were aggregated into years by adding the values of their corresponding months. Parameter " $\omega$ " refers to the watershed characteristics parameter, which displays the capacity of the region to retain water for evapotranspiration based on its land use and cover and water-energy conditions. The " $\omega$ " parameter is linked with soil, topography, and vegetation properties in addition to rainfall and seasonality characteristics ( $\mathrm{Li}$ et al. 2013; Williams et al. 2012; Zhang et al. 2001). It is also dimensionless and can be derived from Eq. 6 (Yang et al. 2008), as given in the following:

$$
\omega=n+0.72
$$

where $n$ is a dimensionless catchment-specific variable. Choudhury (1999) considered a default global value of 1.8 for " $n$." Other studies (Yang et al. 2009; Yang et al. 2008) reported that " $n$ " values are mostly between 1.5 and 2.6. Li et al. (2013) proposed a range of $n$ for 26 major global river basins $\left(>300,000 \mathrm{~km}^{2}\right)$ based on the long-term averaged annual vegetation coverage. Li et al. (2013) found that the basin-specific " $n$ " performs better than the default global value of " $n$." In the Nile river basin, they set a value of " $n$ " as $1.16(\omega=1.88)$. As the purpose of this study is specifically to estimate the temporal evolution of AET, we adopted the Budyko parameters fitted in the Nile basin from Li et al. (2013) to represent the MENA region.

This study also determined the aridity index $(\Psi)$ (Eq. 7) and water availability (Eq. 8).

$$
\Psi=\frac{P E T}{P}
$$

Water availability $=P-A E T$

\section{Results}

\subsection{Assessment of the bias-corrected CMIP6 simulations}

Figure 2 shows a comparison between monthly MENA-averaged precipitation and maximum and minimum temperature simulated by AOGCMs with observations during the reference period. Data are shown before bias correction (Fig. 2 a, b, and c) and after bias correction (Fig. 2d, e, and f). The AOGCM simulations, especially precipitation, have clearer discrepancy with the observations compared with the corrected simulations. After the bias correction, the improved multi-model ensemble median (MEM) precipitation agreed well with the GPCC observations. The correlation coefficient $r=0.92$. For the maximum and minimum 


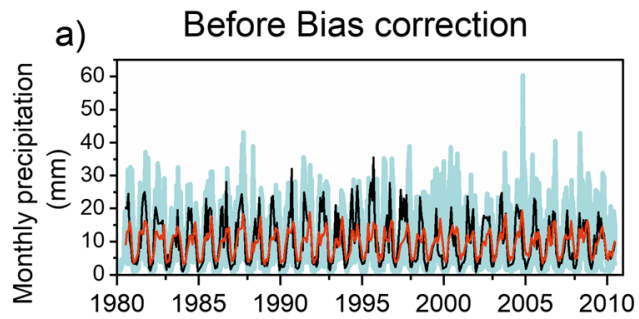

d) After Bias correction

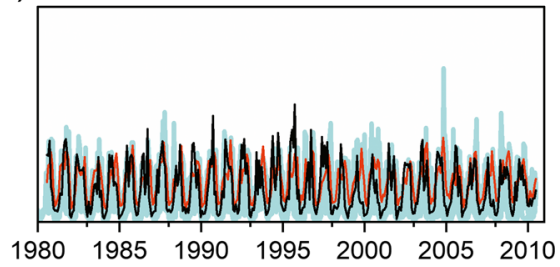

e)

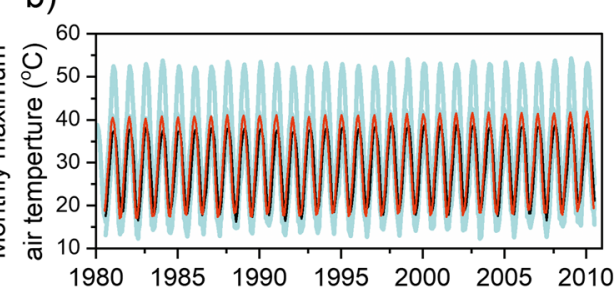

c)

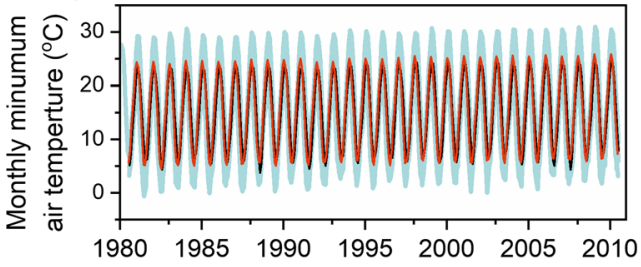

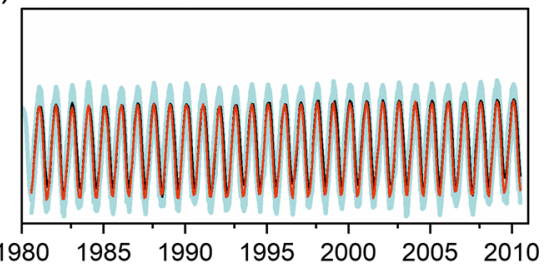

f)

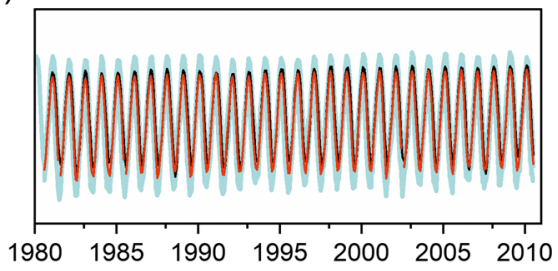

\section{CMIP6 models — Observations}

CMIP6 MEM

Fig. 2 A comparison between the original monthly MENA-averaged precipitation and maximum and minimum temperature CMIP6 simulations with the observations before $(\mathbf{a}, \mathbf{b}$, and $\mathbf{c})$ and after $(\mathbf{d}, \mathbf{e}$, and $\mathbf{f})$ bias correction during 1981-2010. Monthly precipitation was compared with the monthly GPCC observation, while monthly maximum and minimum temperatures were compared with the monthly CRU TS 4.05 data

temperature, it is clear that the AOGCMs simulations had smaller discrepancy (compared with precipitation) with CRU TS observations during the reference period. After applying the bias correction, the correlation between the CMIP6 MEM and the CRU TS observations has improved to 0.98. In general, the bias-corrected precipitation and temperature simulations are able to represent the reference period since they are in good agreement with observational datasets. Therefore, the bias-corrected MEM simulations can predict the future changes in AET and water availability in the MENA region.

\subsection{Temperature and precipitation variations}

Figure 3 illustrates the future variations of the CMIP6 MEM for mean temperature and precipitation in the MENA region through the twenty-first century. Future variations under SSP2-4.5 and SSP5-8.5 are presented as anomalies in ${ }^{\circ} \mathrm{C}$ for mean temperature and as percentages (\%) for precipitation relative to the (1981-2010) average.

Under SSP2-4.5, the monthly temperature was, relative to the reference period, projected to increase by $0.31{ }^{\circ} \mathrm{C}$ by the mid-twenty-first century, and between 1.94 and $2.75^{\circ} \mathrm{C}$ by the endtwenty-first century. High values of temperature increases (during the end-twenty-first century) 


\section{SSP2-4.5}

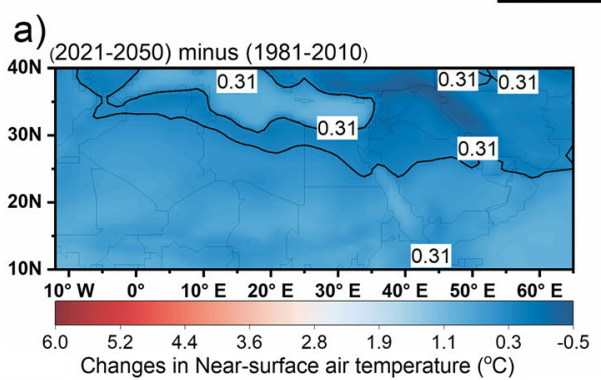

b)

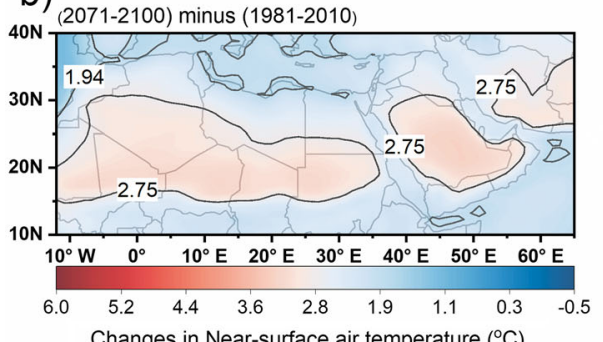

C) (2021-2050) minus (1981-2010)

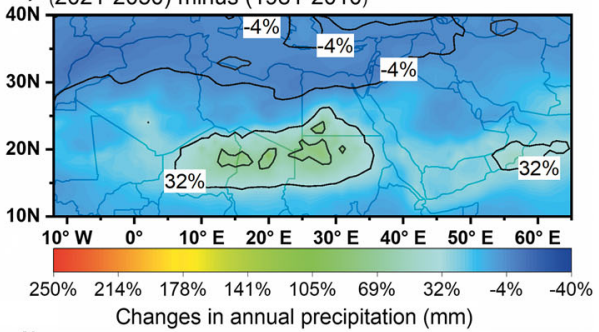

d)

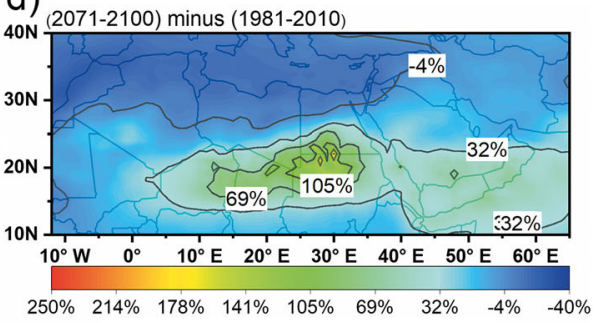
Changes in annual precipitation $(\mathrm{mm})$

\section{SSP5-8.5}

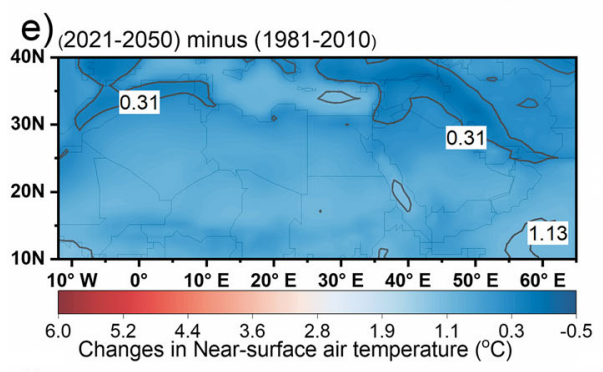

g) (2021-2050) minus (1981-2010)

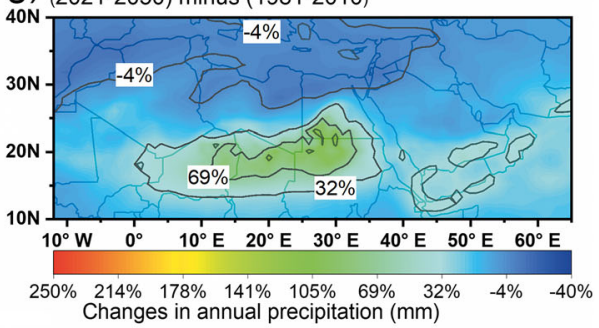

f)

(2071-2100) minus (1981-2010)
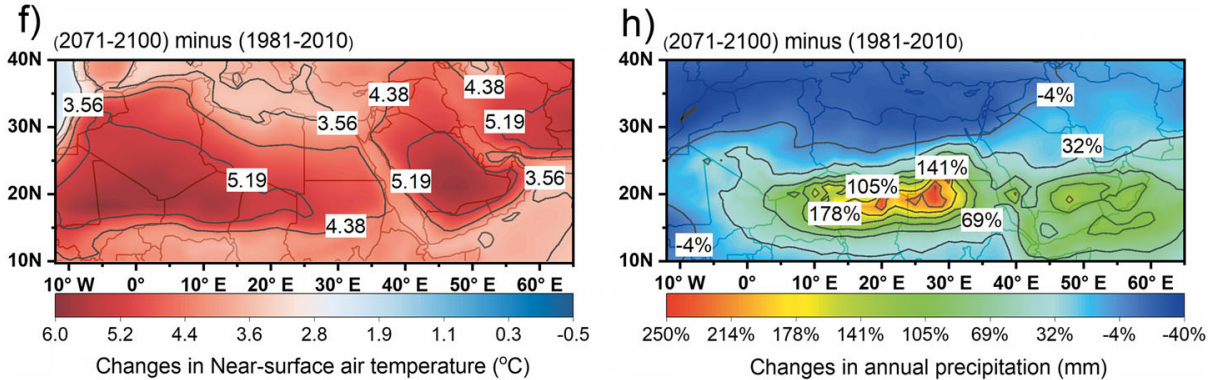

Fig. 3 The CMIP6 multi-model mean projected changes between reference and future periods in monthly nearsurface air temperature in ${ }^{\circ} \mathrm{C}(\mathbf{a}, \mathbf{b}$ and $\mathbf{e}, \mathbf{f})$ and annual precipitation in $\mathrm{mm}(\mathbf{c}, \mathbf{d}$ and $\mathbf{g}, \mathbf{h})$. The top four charts $(\mathbf{a}-$ d) show projections under SSP2-4.5, where the bottom four charts (e-h) show projections under SSP5-8.5

were noted in all MENA regions, except northern parts. Meanwhile, annual precipitation projections displayed substantial variations throughout the MENA region. When compared to 1981-2010, the annual precipitation changed from -4 to $+32 \%$ during the mid-twenty-first 
century. This trend varied at the end-twenty-first century (see Figs. $2 \mathrm{~d}$ and $3 \mathrm{c}$ ). Values of annual precipitation increased (from 32 to $69 \%$ during the end-twenty-first century) in the North African countries, particularly south Egypt and Libya. High values of annual precipitation increased (up to $32 \%$ during the end-twenty-first century) across southern areas of the Arabian Peninsula, particularly in Yemen, Oman, and south Saudi Arabia.

Under SSP5-8.5, the most prominent climatic feature was a surge in temperature, which grew stronger at the end-twenty-first century. The MENA region would have been exposed to temperature increases between 3.56 and $5.19{ }^{\circ} \mathrm{C}$ before 2100 , with high values over the Arabian Gulf countries and south Algeria. Similar to SSP2-4.5, the CMIP6 ensemble projected that annual rainfall would increase in southeastern areas of the MENA region under SSP5-8.5. This increase would hit $105 \%$ in south Egypt and Libya.

\subsection{Potential and actual evapotranspiration variations}

The mean rates of PET throughout the MENA region during both the reference and future periods are displayed in Fig. 4. The PET is projected to rise uniformly across the MENA region. Under SSP2-4.5, the maximum value of annual PET increased from $340 \mathrm{~mm}$ for the reference period to $355 \mathrm{~mm}$ for the mid-twenty-first century and to $386 \mathrm{~mm}$ for the end-twenty-first century. Since the period between 1981 and 2021 (or between 2010 and 2050) is 40 years, the PET increased by up to $0.375 \mathrm{~mm}$ per year before 2050 . The increasing rate of PET is higher through the end of the twenty-first century. Before 2100 , the PET increased by up to $0.51 \mathrm{~mm}$ per year. High values of annual PET were noted in the Arabian Gulf region, while lower values of annual PET ( $\sim 3 \mathrm{~mm})$ were observed in northern Arabian Peninsula — such as Iraq and Iran.
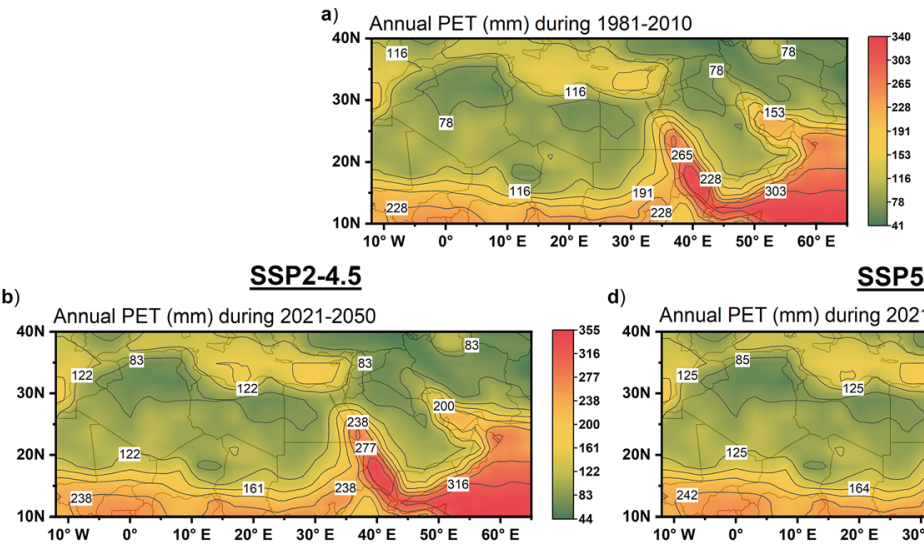

d)

SSP5-8.5
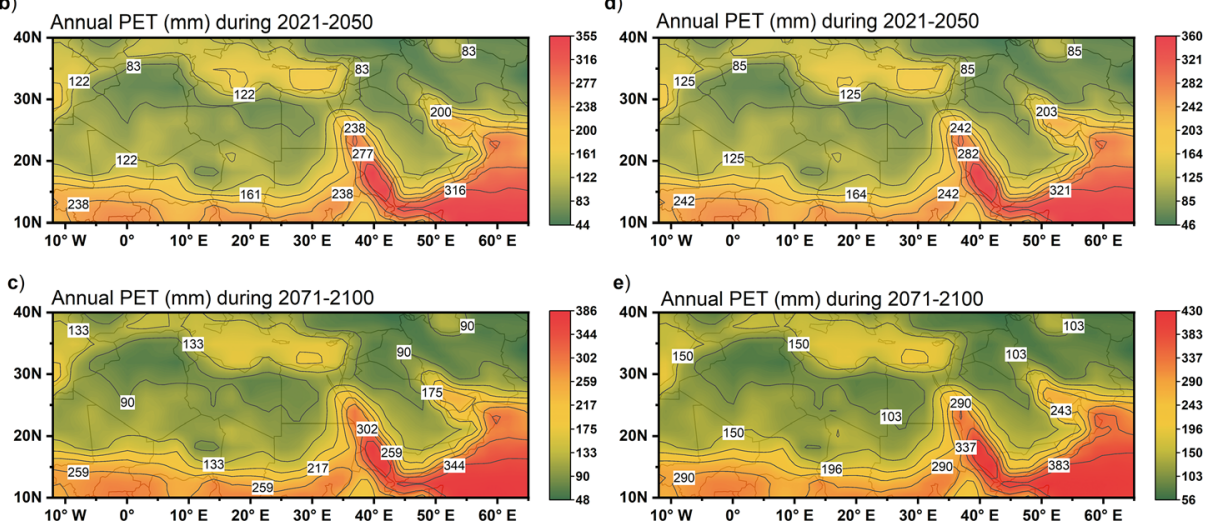

Fig. 4 The CMIP6 multi-model mean projected annual potential evapotranspiration (PET) during (a) the reference period, (b and d) the middle of the twenty-first century, and (c and e) the end of the twenty-first century. The maps (b and c) show projections under SSP2-4.5, whereas (d and e) maps show projections under SSP5-8.5 
The PET losses increased significantly at the end-twenty-first century under SSP5-8.5. The analysis revealed that maximum annual PET is projected to increase by $90 \mathrm{~mm}$ during the endtwenty-first century $(430-340 \mathrm{~mm})$ relative to the reference period. This increase proposes a pronounced increased rate of PET at $1 \mathrm{~mm}_{\text {year }}{ }^{-1}$.

By implementing the Budyko framework, annual AET values were derived across the MENA region under SSP2-4.5 and SSP5-8.5. Figure 5 illustrates the annual AET values during reference and future periods. Under SSP2-4.5, the annual AET varied up to $109 \mathrm{~mm}$ for the reference period, while up to $121 \mathrm{~mm}$ for the mid-twenty-first century and up to $126 \mathrm{~mm}$ for the end-twenty-first century. In other words, the AET is expected to rise by up to $0.3(0.19)$ $\mathrm{mm}$ per year before 2050 (2100). High values of annual AET were noted in the north Arabian Gulf, while most other MENA areas had low values of annual AET $(<63$ mm under SSP2$4.5)$ during the two future periods. Very low values of annual AET $(<32 \mathrm{~mm}$ under SSP2 -4.5$)$ were observed in south Egypt and Libya during the end-twenty-first century, which can be attributed to the precipitation increase projections in these regions (see Fig. 2).

The AET losses increased during the end-twenty-first century based on SSP5-8.5. The analysis showed that the maximum annual AET is projected to increase by $32 \mathrm{~mm}$ (141$109 \mathrm{~mm}$ ) during the end-twenty-first century relative to the reference period. This increase proposes a significant growing rate of AET up to $0.35 \mathrm{~mm}$ per year.

\subsection{Aridity index and water availability variations}

Generally, the aridity index (PET/precipitation) is projected to see a slight increase in the twenty-first century (up to 0.15 ) throughout the MENA region. As portrayed in Fig. 6, the aridity index varied up to 0.48 for the reference period as well as up to 0.62 for the future
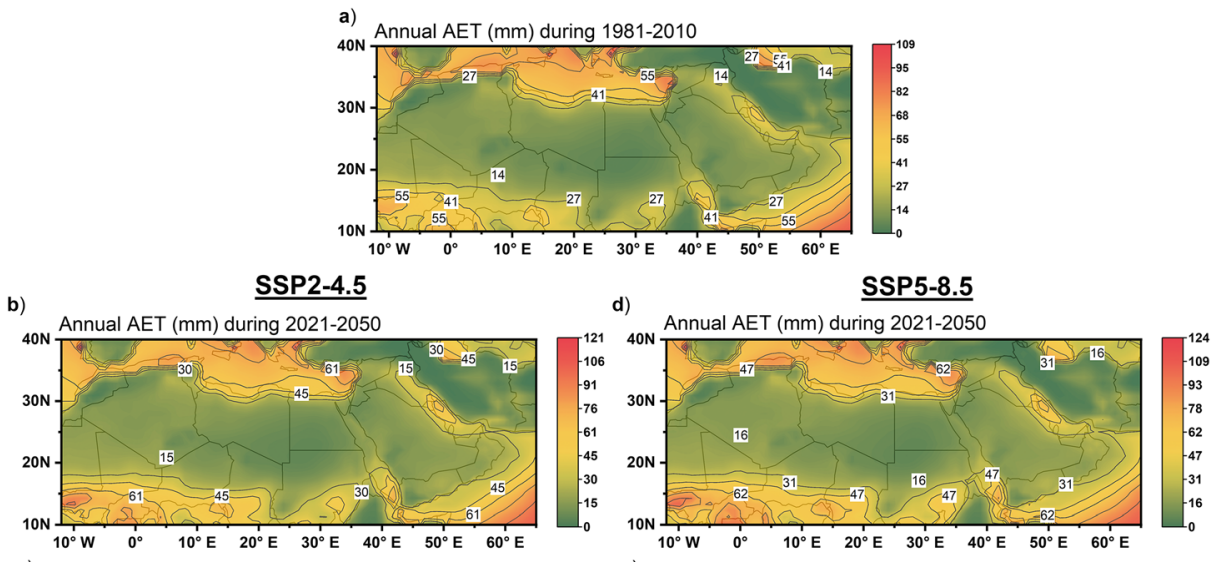

c)

e)
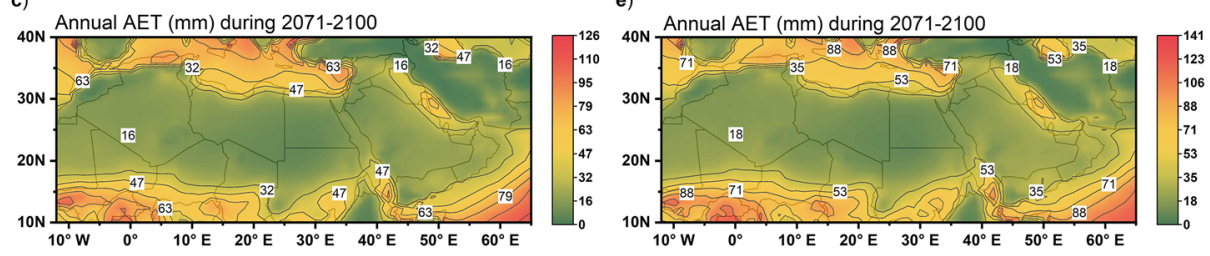

Fig. 5 The CMIP6 multi-model mean projected annual actual evapotranspiration (AET) during (a) the reference period, (b and d) the middle of the twenty-first century, and (c and e) the end of the twenty-first century. The maps (b and c) show projections under SSP2-4.5, whereas (d and e) maps show projections under SSP5-8.5 


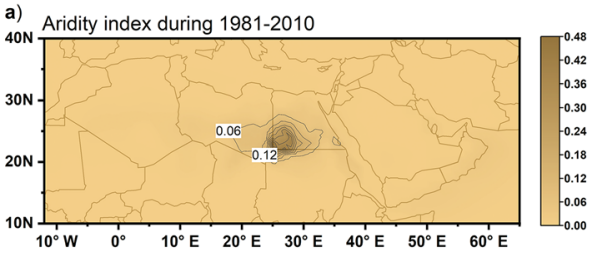

SSP2-4.5

b)

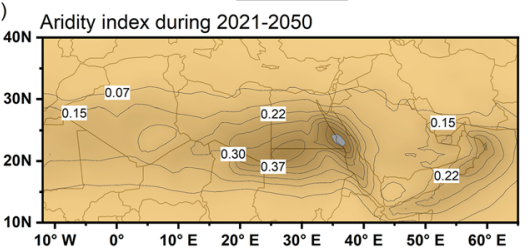

c) Aridity index during 2071-2100

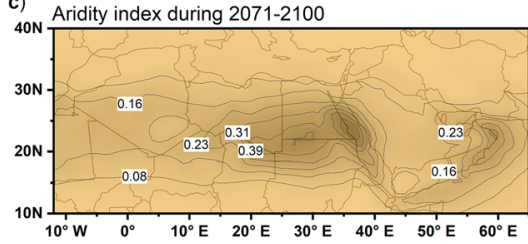

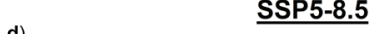

d) Aridity index during 2021-2050
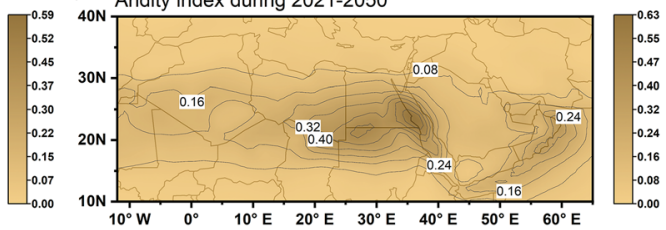

e)

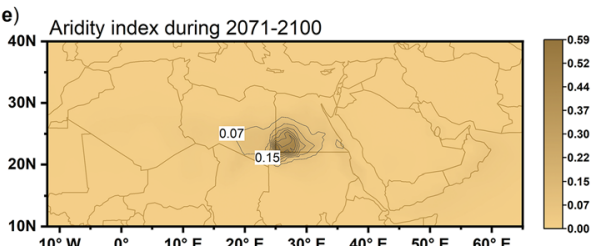

Fig. 6 The CMIP6 multi-model mean projected aridity index during (a) the reference period, (b and d) the middle of the twenty-first century, and (c and e) the end of the twenty-first century. The maps (b and c) show projections under SSP2-4.5, whereas (d and e) maps show projections under SSP5-8.5

periods under SSP2-4.5. Maximum values of the aridity index, 0.22-0.39, were noted north of the Red Sea, whereas other MENA areas had values of the aridity index less than 0.23 . Variations in the aridity index were not substantial between SSP2-4.5 and SSP5-8.5 during the mid-twenty-first century. Only a slight decrease was noticed under SSP5-8.5 in the Red Sea and south Egypt regions, relative to SSP2-4.5, during the end-twenty-first century (see Fig. $6 \mathrm{c}$ and e). Under the SSP5-8.5, MENA aridity increases, and very low values of the aridity index $(<0.07)$ dominate most regions in the end-twenty-first century.

The water availability component revealed more spatial variability throughout the MENA region. Figure 7 shows that relative to the reference period, the MENA appeared vulnerable to water deficit with a significant shortage in all countries. Under SSP2-4.5, annual water availability is projected to decrease approximately $26 \mathrm{~mm}(102-76)$ through 2100 relative to the reference period in all MENA regions. In other words, annual water availability decreased at $0.29 \mathrm{~mm}$ per year under SSP2-4.5. Not many changes were observed between the middle of the twenty-first-century projections for annual water availability under SSP2-4.5 and SSP58.5, as Fig. $7 \mathrm{~b}$ and $\mathrm{d}$ show. This is ascribed to the projected increase in precipitation values in some areas of the MENA region, which increased water availability (precipitation-AET) in these areas. On the other hand, water availability changes were apparent under SSP5-8.5 throughout the end-twenty-first century. A comparison between SSP2-4.5 and SSP5-8.5 in Fig. 7 displayed that, except in east Yemen, the maximum annual MENA water availability, in 2100, decreased from $76 \mathrm{~mm}$ under SSP2-4.5 to $40 \mathrm{~mm}$ under SSP5-8.5. Considering that the variation period is 90 years, the difference occurred between 1981 and 2071 (or between 2010 and 2100). Therefore, on an annual scale, water availability decreased an extra $0.4 \mathrm{~mm}_{\text {year }}{ }^{-1}$ under SSP5-8.5, compared to SSP2-4.5. 

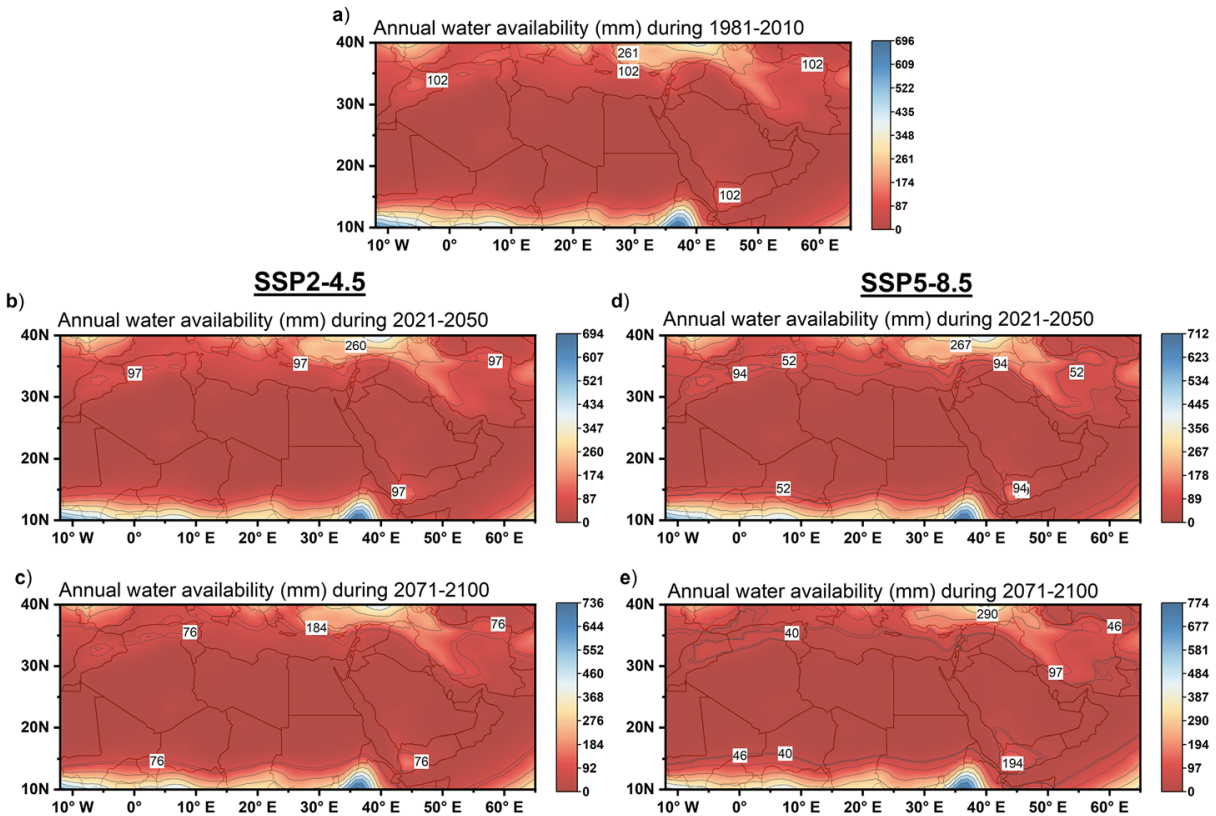

Fig. 7 The CMIP6 multi-model mean projected annual water availability during (a) the reference period, (b and d) the middle of the twenty-first century, and (c and e) the end of the twenty-first century. The maps (b and c) show projections under SSP2-4.5, whereas (d and e) maps show projections under SSP5-8.5

\section{Summary and discussion}

The present study investigated the evolutions of evapotranspiration and water availability throughout the twenty-first century across the MENA region. The analysis under SSP2-4.5 revealed that PET and AET would increase by up to $0.37 \mathrm{~mm}$ per year during the mid-twentyfirst century (2021-2050). The PET rate would further increase by approximately $136 \%$ during the end-twenty-first century (2071-2100). The increasing trend in PET and AET over the MENA region is in line (to some extent) with that reported in the literature during past decades. Anabalón and Sharma (2017) noticed that the global PET (AET) increased at 1.09 (0.54) mm per year during 1980-2012. The trend reported by Anabalón and Sharma (2017) was clearly represented in water-limited regions like the MENA. Jung et al. (2010) and Wang et al. (2010) suggested higher values of global AET increments. Jung et al. (2010) found that global AET increased by $7.1 \pm 1.0 \mathrm{~mm}$ per year during 1982-1997, whereas Wang et al. (2010) suggested an AET increasing rate of $15 \mathrm{~mm}$ per year during 1982-2002. In this study, the maximum decrease in MENA annual water availability would hit $26 \mathrm{~mm}$ in 2100 under SSP2-4.5, and the latter value was $62 \mathrm{~mm}$ under SSP5-8.5. These findings are consistent with those of McCabe and Wolock (2015), who demonstrated that the region with latitude band 0 $40^{\circ} \mathrm{N}$ had experienced the most considerable decrease in water availability globally between 1905 and 2009. Another study in Iran (Tabari and Talaee 2014) found that arid regions experienced the greatest change in PET. This present analysis showed that global warming would keep pressurizing water deficits in the MENA region through the twenty-first century.

During the mid-twenty-first century, slight changes were noted between SSP2-4.5 and SSP5-8.5 in the heat, PET, AET, and aridity indices. On the contrary, the variations were larger (and clearer) in all terms (except the aridity index) during the end-twenty-first century 
between SSP2-4.5 and SSP5-8.5. This is compatible with the powerful atmospheric demand control on evapotranspiration. Sullivan et al. (2019) reported that the global trend in AET was $0.17-0.34 \mathrm{~mm}$ per year, which appeared greater in SSP5-8.5 relative to SSP2-4.5. This present analysis found that the AET trend was up to $0.17 \mathrm{~mm}$ per year, greater in SSP5-8.5 relative to SSP2-4.5 (see the differences in Fig. $5 \mathrm{c}$ and e). It can be concluded, then, that arid environments are attributed to greater losses in AET than other climates.

Prior work had reported different parameters that affected PET estimations. Gong et al. (2006) found that the most sensitive variables to PET in the Yangtze River basin (China) were in the following order: relative humidity $\succ$ shortwave radiation $\succ$ air temperature $\succ$ wind speed. Irmak et al. (2006) discovered that daily PET in different climatic conditions (semiarid, Mediterranean, and humid) across the US appeared to be sensitive mainly to vapor pressure deficits followed by wind speed. Using the physically based method (Penman 1948) helped considering the most important variables that govern the evaporation process in the MENA region. As for AET and water availability, their sensitivities can be linked mainly to temperature rises across the whole MENA area. Through the twenty-first century, the MEM of 10 CMIP6 models projected temperature increases of up to 2.75 (5.2) ${ }^{\circ} \mathrm{C}$ under SSP2-4.5 (SSP58.5) while projecting variant trends in rainfall direction and magnitude across the MENA region. However, AET increased and water availability decreased relatively uniformly throughout all MENA areas. This suggests that temperature upsurge is the principal reason for evapotranspiration and water availability responses in arid areas. The latter finding is in line with Tabari and Talaee (2014) who reported that AET is primarily driven by temperature trends in arid regions across Iran. The situation may differ in humid regions where AET is influenced by different variables. For example, Anabalón and Sharma (2017) suggested that AET in the Amazon Basin and central Europe was affected largely by vegetation cover, and Sullivan et al. (2019) revealed that the AET's sensitivity was due primarily to the temperature trend over North America.

This work may carry some uncertainties. First, PET and AET are complex phenomena and may not be represented ideally using the Penman (1948) and Budyko and Miller (1974) formulas. The literature has suggested larger uncertainties in PET estimations. Although using the physically based reliable Penman (1948) method incorporates more variables and hence bridge some gaps, local calibration of these variables over the MENA might still be required. Regarding AET estimation, Wang et al. (2018) and Feng et al. (2019) concluded that the Budyko approach can better predict AET in non-humid areas (compared to humid areas). Hence, the uncertainty in AET estimation is smaller than that of PET. Second, the uncertainty surrounding GHG emission scenarios and the CMIP6 models should lead to subsequent uncertainty in future projections of evapotranspiration and water availability throughout the MENA region. Previous literature found larger uncertainties in CMIP models compared with emission scenarios (Wu et al. 2021; Xu et al. 2019). In this study, the original CMIP6 simulations were not able to accurately project the climatic changes across the MENA through 2100-especially rainfall. Rainfall is a major component in the Budyko framework, meaning that small inaccuracy in rainfall projections could lead to inaccuracy in AET estimations. Using an ensemble of the CMIP6 models as well as correcting the bias as proposed in this study helps bridge the gap. Furthermore, this study's aim was not to give ground truth estimations at local scales but to estimate the evapotranspiration and water availability evolutions through the twenty-first century. 


\section{Conclusion}

Integrating the Penman (1948) and Budyko and Miller (1974) approaches with temperature, precipitation, wind speed, radiation, and relative humidity simulations in CMIP6 model projects changes in evapotranspiration and water availability (through 2100) across the MENA region. Comparing future periods (through the twenty-first century) with the historical (reference) period (1981-2010) offers guidance to policymakers and scientists for establishing climate change adaptation and mitigation measurements apart from managing water resources effectively. The temperature surge over the MENA region seemed to increase PET losses. The increase in PET amplified AET but declined water availability significantly during the twentyfirst century. This implies substantial changes in components of the hydrological cycle, which increased the imbalance between water supply and demand across the MENA region (Ajjur and Baalousha 2021). The study's outcomes are valuable, especially when ground data are unavailable. However, further regional work is warranted, especially in humid areas of the MENA region. This work should be followed by an assessment of how the projected changes in evapotranspiration can affect water resources, land cover, and soil moisture as well as runoff at regional scales. Such knowledge helps to increase the resilience of the MENA region's fragile systems against climatic changes.

Acknowledgements The authors thank the World Climate Research Programme (WCRP), which made the CMIP6 data available, and the CMIP6 modeling groups (institutions). The authors also thank NOAA physical sciences laboratory for providing the GPCC Precipitation data and the University of East Anglia for providing the CRU TS gridded temperature datasets.

Author contribution Conceptualization, methodology, analysis, and writing - first draft preparation: Salah Ajjur; Review and editing: Sami Al-Ghamdi and Salah Ajjur.

Funding This work was made possible through a PhD scholarship from Hamad Bin Khalifa University (HBKU), a member of Qatar Foundation (QF) to Salah Ajjur, and by the National Priorities Research Program (NPRP) grant (NPRP12S-0212-190073) from the Qatar National Research Fund (QNRF), a member of Qatar Foundation (QF) to Sami G. Al-Ghamdi. Any opinions, findings, conclusions, or recommendations expressed in this materials are those of the authors and do not necessarily reflect the views of HBKU, QNRF or QF. Open Access funding provided by the Qatar National Library.

Data availability All maps are available as gridded data layers from the corresponding authors on reasonable request. Hydrologists, climatologists, and decision-makers can use these maps to determine areas with high evapotranspiration and water deficit projections.

\section{Declarations}

Ethical approval No part of the manuscript has been published before, nor it is under consideration at another journal.

Consent to participate Not applicable.

Consent for publication The authors transfer to Springer the non-exclusive publication rights, and they warrant that their contribution is original and that they have full power to make this grant. 
Conflict of interest The authors declare no competing interests.

Open Access This article is licensed under a Creative Commons Attribution 4.0 International License, which permits use, sharing, adaptation, distribution and reproduction in any medium or format, as long as you give appropriate credit to the original author(s) and the source, provide a link to the Creative Commons licence, and indicate if changes were made. The images or other third party material in this article are included in the article's Creative Commons licence, unless indicated otherwise in a credit line to the material. If material is not included in the article's Creative Commons licence and your intended use is not permitted by statutory regulation or exceeds the permitted use, you will need to obtain permission directly from the copyright holder. To view a copy of this licence, visit http://creativecommons.org/licenses/by/4.0/.

\section{References}

Ajjur SB, Riffi MI (2020) Analysis of the observed trends in daily extreme precipitation indices in Gaza strip during 1974-2016. Int J Climatol 40:6189-6200. https://doi.org/10.1002/joc.6576

Ajjur, S.B., Baalousha, H.M. (2021) A review on implementing managed aquifer recharge in the Middle East and North Africa region: methods, progress and challenges. Water International 1-27. https://doi.org/10.1080/ 02508060.2021 .1889192 .

Anabalón A, Sharma A (2017) On the divergence of potential and actual evapotranspiration trends: an assessment across alternate global datasets. Earth's Future 5:905-917. https://doi.org/10.1002/2016ef000499

Baw-Puh F (1981) On the calculation of the evaporation from land surface [in Chiness]. Chin J Atmos Sci 1:002

Blaney HF, Criddle WD (1950) Determining water requirements in irrigated area from climatological irrigation data, US Department of Agriculture, Soil Conservation Service. Tech Pap 96:48

Brêda JPLF, de Paiva RCD, Collischon W, Bravo JM, Siqueira VA, Steinke EB (2020) Climate change impacts on South American water balance from a continental-scale hydrological model driven by CMIP5 projections. Clim Chang 159:503-522. https://doi.org/10.1007/s10584-020-02667-9

Budyko MI, Miller DH (1974) Climate and life. vol 508. Academic press New York,

Choudhury B (1999) Evaluation of an empirical equation for annual evaporation using field observations and results from a biophysical model. J Hydrol 216:99-110. https://doi.org/10.1016/S0022-1694(98)00293-5

Dalton J (1802) Experimental essays on the constitution of mixed gases: on the force of steam or vapor from water or other liquids in different temperatures, both in a torricelli vacuum and in air; on evaporation; and on expansion of gases by heat', manchester literary philosophical society mem. Proceedings 5:536-602

Dezsi Ș, Mîndrescu M, Petrea D, Rai PK, Hamann A, Nistor M-M (2018) High-resolution projections of evapotranspiration and water availability for Europe under climate change. Int J Climatol 38:3832-3841. https://doi.org/10.1002/joc.5537

Diak GR, Mecikalski JR, Anderson MC, Norman JM, Kustas WP, Torn RD, DeWolf RL (2004) Estimating Land Surface Energy Budgets From Space: Review and Current Efforts at the University of WisconsinMadison and USDA-ARS Bulletin of the American. Meteorological Society 85:65-78. https://doi.org/10. 1175/bams-85-1-65

Dong B, Dai A (2016) The uncertainties and causes of the recent changes in global evapotranspiration from 1982 to 2010. Clim Dyn 49:279-296. https://doi.org/10.1007/s00382-016-3342-x

Donohue RJ, Roderick ML, McVicar TR (2012) Roots, storms and soil pores: incorporating key ecohydrological processes into Budyko's hydrological model. J Hydrol 436-437:35-50. https://doi.org/10.1016/j.jhydrol. 2012.02.033

Doorenbos J (1975) Guidelines for predicting crop water requirements J Food Agriculture organization Rome, Irrig Drainage pap 24

Eichelmann E et al (2018) The effect of land cover type and structure on evapotranspiration from agricultural and wetland sites in the Sacramento-San Joaquin River Delta. California Agricultural and Forest Meteorology 256-257:179-195. https://doi.org/10.1016/j.agrformet.2018.03.007

Erol A, Randhir TO (2012) Climatic change impacts on the ecohydrology of Mediterranean watersheds. Clim Chang 114:319-341. https://doi.org/10.1007/s10584-012-0406-8

Feng T, Su T, Zhi R, Tu G, Ji F (2019) Assessment of actual evapotranspiration variability over global land derived from seven reanalysis datasets. Int J Climatol 39:2919-2932. https://doi.org/10.1002/joc.5992

Gong L, Xu C-y, Chen D, Halldin S, Chen YD (2006) Sensitivity of the Penman-Monteith reference evapotranspiration to key climatic variables in the Changjiang (Yangtze River) basin. J Hydrol 329:620629. https://doi.org/10.1016/j.jhydrol.2006.03.027 
Goya MR, Harmsen EW (2014) Evapotranspiration principles and applications for water management. https:// doi.org/10.1201/b15779

Hargreaves GH, Samni ZA (1982) Estimation of potential evapotranspiration. J Irrig Drain Eng, Proceedings of the American Society of Civil Engineers 108(3):223-230

Harris I, Osborn TJ, Jones P, Lister D (2020) Version 4 of the CRU TS monthly high-resolution gridded multivariate climate dataset. Scientific Data 7:109. https://doi.org/10.1038/s41597-020-0453-3

Hay LE, Wilby RL, Leavesley GH (2000) A comparison of delta change and downscaled GCM scenarios for three mountainous basins in the United States. J Am Water Resour Assoc 36:387-397. https://doi.org/10. 1111/j.1752-1688.2000.tb04276.x

IPCC (2014) Climate change 2014: synthesis report. Contribution of working groups I, II and III to the fifth assessment report of the intergovernmental panel on climate change [Core writing team, R.K. Pachauri and L.a. Meyer (eds.)]. Geneva, Switzerland

Irmak S, Payero JO, Martin DL, Irmak A, Howell TA (2006) Sensitivity analyses and sensitivity coefficients of standardized daily ASCE-Penman-Monteith Equation. J Irrig Drain Eng 132:564-578. https://doi.org/10. 1061/(ASCE)0733-9437(2006)132:6(564)

Jung $\mathrm{M}$ et al (2010) Recent decline in the global land evapotranspiration trend due to limited moisture supply. Nature 467:951-954. https://doi.org/10.1038/nature09396

Lelieveld J, Proestos Y, Hadjinicolaou P, Tanarhte M, Tyrlis E, Zittis G (2016) Strongly increasing heat extremes in the Middle East and North Africa (MENA) in the 21st century. Clim Chang 137:245-260. https://doi.org/ 10.1007/s10584-016-1665-6

Li D, Pan M, Cong Z, Zhang L, Wood E (2013) Vegetation control on water and energy balance within the Budyko framework. Water Resour Res 49:969-976. https://doi.org/10.1002/wrcr.20107

Li S, Kang S, Zhang L, Zhang J, Du T, Tong L, Ding R (2016) Evaluation of six potential evapotranspiration models for estimating crop potential and actual evapotranspiration in arid regions. J Hydrol 543:450-461. https://doi.org/10.1016/j.jhydrol.2016.10.022

Li Z, Li Q, Wang J, Feng Y, Shao Q (2020) Impacts of projected climate change on runoff in upper reach of Heihe River basin using climate elasticity method and GCMs Science of The Total Environment 716: 137072 https://doi.org/10.1016/j.scitotenv.2020.137072

Makkink GF (1957) Testing the Penman formula by means of lysimeters. Journal of the Institution of Water Engineers 11:277-288

McCabe GJ, Wolock DM (2015) Increasing Northern Hemisphere water deficit. Clim Chang 132:237-249. https://doi.org/10.1007/s10584-015-1419-x

Mueller B, Seneviratne SI (2014) Systematic land climate and evapotranspiration biases in CMIP5 simulations. Geophys Res Lett 41:128-134. https://doi.org/10.1002/2013GL058055

Nastos PT (2011) Trends and variability of precipitation within the Mediterranean region, based on Global Precipitation Climatology Project (GPCP) and ground based datasets. In: Lambrakis N, Stournaras G, Katsanou K (eds) Advances in the research of aquatic environment, Springer, vol 1. Berlin Heidelberg, Berlin, Heidelberg, pp 67-74. https://doi.org/10.1007/978-3-642-19902-8_ 7

Peel MC, Finlayson BL, McMahon TA (2007) Updated world map of the Koppen-Geiger climate classification hydrology and earth system. Sciences 11:1633-1644. https://doi.org/10.5194/hess-11-1633-2007

Penman HL (1948) Natural evaporation from open water, bare soil and grass. In: Proceedings of the Royal Society of London. Series A. Mathematical Physical Sciences 1032:120-145

Pielke RA, Avissar R, Raupach M, Dolman AJ, Zeng X, Denning AS (2003) Interactions between the atmosphere and terrestrial ecosystems: influence on weather and climate. Glob Chang Biol 4:461-475. https://doi.org/10.1046/j.1365-2486.1998.t01-1-00176.x

Priestley CHB, Taylor RJ (1972) On the assessment of surface heat flux and evaporation using large-scale parameters. Mon Weather Rev 100:81-92

Rahimi-Moghaddam S, Kambouzia J, Deihimfard R (2018) Adaptation strategies to lessen negative impact of climate change on grain maize under hot climatic conditions: a model-based assessment. Agric For Meteorol 253-254:1-14. https://doi.org/10.1016/j.agrformet.2018.01.032

Shuttleworth WJ (1993) Evaporation. In: Maidment DR (ed) Handbook of hydrology. McGraw-Hill, Now York

Sullivan RC, Kotamarthi VR, Feng Y (2019) Recovering evapotranspiration trends from biased CMIP5 simulations and sensitivity to changing climate over North America. J Hydrometeorol 20:1619-1633. https://doi.org/10.1175/jhm-d-18-0259.1

Tabari H, Talaee PH (2014) Sensitivity of evapotranspiration to climatic change in different climates. Glob Planet Chang 115:16-23. https://doi.org/10.1016/j.gloplacha.2014.01.006

Wang K, Dickinson RE, Wild M, Liang S (2010) Evidence for decadal variation in global terrestrial evapotranspiration between 1982 and 2002: 2. Results Journal of Geophysical Research 115. https://doi.org/10. 1029/2010jd013847 
Wang W, Li C, Xing W, Fu J (2017) Projecting the potential evapotranspiration by coupling different formulations and input data reliabilities: the possible uncertainty source for climate change impacts on hydrological regime. J Hydrol 555:298-313. https://oi.org/10.1016/j.jhydrol.2017.10.023

Wang T, Sun F, Lim WH, Wang H, Liu W, Liu C (2018) The predictability of annual evapotranspiration and runoff in humid and nonhumid catchments over China: comparison and quantification. J Hydrometeorol 19: 533-545. https://doi.org/10.1175/jhm-d-17-0165.1

Williams CA et al (2012) Climate and vegetation controls on the surface water balance: synthesis of evapotranspiration measured across a global network of flux towers. Water Resour Res:48. https://doi.org/10. 1029/2011wr011586

WMO (2017) World Meteorological Organization Guidelines on the Calculation of Climate Normals vol 2019

Wu C, Huang G (2016) Projection of climate extremes in the Zhujiang River basin using a regional climate model. Int J Climatol 36:1184-1196. https://doi.org/10.1002/joc.4412

Wu C, Hu BX, Huang G, Wang P, Xu K (2018) Responses of runoff to historical and future climate variability over China. Hydrol Earth Syst Sci:1971-1991. https://doi.org/10.5194/hess-22-1971-2018

Wu C, Yeh PJF, Chen Y-Y, Hu BX, Huang G (2020) Future precipitation-driven meteorological drought changes in the CMIP5 multimodel ensembles under $1.5^{\circ} \mathrm{C}$ and $2^{\circ} \mathrm{C}$ global warming. $\mathrm{J}$ Hydrometeorol 21 : 2177-2196. https://doi.org/10.1175/jhm-d-19-0299.1

$\mathrm{Wu} \mathrm{C}$ et al (2021) Assessing the spatiotemporal uncertainties in future meteorological droughts from CMIP5 models, emission scenarios, and bias corrections. J Clim 34:1903-1922. https://doi.org/10.1175/jcli-d-200411.1

Xu K, Xu B, Ju J, Wu C, Dai H, Hu BX (2019) Projection and uncertainty of precipitation extremes in the CMIP5 multimodel ensembles over nine major basins in China. Atmos Res 226:122-137. https://doi.org/10. 1016/j.atmosres.2019.04.018

Yang H, Yang D, Lei Z, Sun F (2008) New analytical derivation of the mean annual water-energy balance equation. Water Resour Res:44. https://doi.org/10.1029/2007wr006135

Yang D, Shao W, Yeh PJF, Yang H, Kanae S, Oki T (2009) Impact of vegetation coverage on regional water balance in the nonhumid regions of China. Water Resour Res:45. https://doi.org/10.1029/2008wr006948

Zhang L, Dawes WR, Walker GR (2001) Response of mean annual evapotranspiration to vegetation changes at catchment scale. Water Resour Res 37:701-708. https://doi.org/10.1029/2000wr900325

Zhang Y, Kong D, Gan R, Chiew FHS, McVicar TR, Zhang Q, Yang Y (2019) Coupled estimation of $500 \mathrm{~m}$ and 8-day resolution global evapotranspiration and gross primary production in 2002-2017. Remote Sens Environ 222:165-182. https://doi.org/10.1016/j.rse.2018.12.031

Zittis G (2017) Observed rainfall trends and precipitation uncertainty in the vicinity of the Mediterranean, Middle East and North Africa Theoretical and Applied. Climatology 134:1207-1230. https://doi.org/10.1007/ s00704-017-2333-0

Publisher's note Springer Nature remains neutral with regard to jurisdictional claims in published maps and institutional affiliations. 